\title{
Dissociable Roles of Prelimbic and Infralimbic Cortices, Ventral Hippocampus, and Basolateral Amygdala in the Expression and Extinction of Conditioned Fear
}

\author{
Demetrio Sierra-Mercado', Nancy Padilla-Coreano', Gregory J Quirk*,I \\ 'Departments of Psychiatry and Anatomy and Neurobiology, University of Puerto Rico School of Medicine, San Juan, PR, USA
}

\begin{abstract}
Current models of conditioned fear expression and extinction involve the basolateral amygdala (BLA), ventral medial prefrontal cortex (vmPFC), and the hippocampus (HPC). There is some disagreement with respect to the specific roles of these structures, perhaps due to subregional differences within each area. For example, growing evidence suggests that infralimbic $(\mathrm{IL})$ and prelimbic $(\mathrm{PL})$ subregions of vmPFC have opposite influences on fear expression. Moreover, it is the ventral HPC (vHPC), rather than the dorsal HPC, that projects to VmPFC and BLA. To help determine regional specificity, we used small doses of the GABA Agonist muscimol to selectively inactivate IL, $\mathrm{PL}, \mathrm{BLA}$, or $\mathrm{VHPC}$ in an auditory fear conditioning and extinction paradigm. Infusions were performed prior to extinction training, allowing us to assess the effects on both fear expression and subsequent extinction memory. Inactivation of IL had no effect on fear expression, but impaired the within-session acquisition of extinction as well as extinction memory. In contrast, inactivation of PL impaired fear expression, but had no effect on extinction memory. Inactivation of the BLA or vHPC impaired both fear expression and extinction memory. Post-extinction inactivations had no effect in any structure. We suggest a model in which amygdala-dependent fear expression is modulated by inputs from PL and VHPC, whereas extinction memory requires extinction-induced plasticity in IL, BLA, and/or vHPC. Neuropsychopharmacology (20II) 36, 529-538; doi:I0.1038/npp.2010.184; published online 20 October 2010
\end{abstract}

Keywords: rat; inactivation; prefrontal cortex; conditioning; muscimol; GABA

\section{INTRODUCTION}

There is increasing interest in the neural circuits that mediate extinction of conditioned fear. Extinction can be thought of as a form of fear regulation, in which potentiation of inhibitory circuits reduces the expression of fear memories, contingent upon temporal and contextual factors. For auditory fear conditioning, there is a general consensus that extinction involves three main structures: the amygdala, the prefrontal cortex (PFC), and the hippocampus (HPC) (Quirk and Mueller, 2008). The basolateral amygdala (BLA), a storage site for fear memories, is thought to mediate the initial acquisition of extinction (Herry et al, 2006, 2008; Sotres-Bayon et al, 2007) and the expression of extinction memory via inhibition of central amygdala (CeA) output neurons (Quirk et al, 2003; Likhtik et al, 2008). Plasticity in the ventral medial PFC (vmPFC) is important for the retrieval of extinction memory (Morgan et al, 1993; Milad and Quirk, 2002; Quirk

*Correspondence: Dr GJ Quirk, Departments of Psychiatry and Anatomy and Neurobiology, University of Puerto Rico School of Medicine, San Juan, PR 00936-5067, USA, Tel: + I 787999 3, Fax: + I 787999 3057, E-mail: gjquirk@yahoo.com

Received 16 August 2010; accepted II September 2010 et al, 2006; Sotres-Bayon et al, 2006), and the HPC is thought to mediate the contextual gating of extinction (Corcoran et al, 2005; Hobin et al, 2006).

Despite the consensus that these three areas are important for fear expression and extinction memory, there are conflicting findings in studies used to evaluate the specific roles of each area. Such conflicting findings may be due to the fact that each of these structures is composed of specific subregions that have different roles in fear expression and extinction. For example, the vmPFC is composed of the infralimbic cortex (IL) ventrally and the prelimbic cortex (PL) dorsally. Recent electrophysiological findings suggest that IL and PL have opposite influences on fear expression (Gilmartin and McEchron, 2005; VidalGonzalez et al, 2006), and have different targets within the amygdala (Vertes, 2004; Gabbott et al, 2005). Yet, prior inactivation studies using either the $\mathrm{GABA}_{\mathrm{A}}$ agonist muscimol or the sodium channel blocker tetrodotoxin (TTX) into vmPFC used a midline infusion or large volumes of the drug, which did not allow a distinction between these subregions (Akirav et al, 2006; Sierra-Mercado et al, 2006). This approach may be the cause of conflicting reports of either impairment (Sierra-Mercado et al, 2006; Laurent and Westbrook, 2008) or facilitation (Akirav et al, 2006) of extinction following vmPFC inactivation. Similarly, 
administration of pharmacological blockers in BLA impair extinction memory (Falls et al, 1992; Herry et al, 2006), whereas lesions of BLA do not (Sotres-Bayon et al, 2004; Anglada-Figueroa and Quirk, 2005). Furthermore, prior studies of the HPC in extinction have focused on the dorsal subdivision (dHPC), despite the fact that it is the ventral subdivision (vHPC) that projects to the vmPFC and BLA (Pitkanen et al, 2000; Hoover and Vertes, 2007). Lesions of vHPC have been shown to reduce fear expression (Maren and Holt, 2004), but the effects of vHPC lesions on extinction have not been examined.

In order to clarify the roles of these areas in fear expression and extinction, we infused low doses of muscimol (or saline) bilaterally to selectively inactivate IL, PL, BLA, or vHPC. Infusions were performed shortly prior to extinction training, thereby allowing us to dissociate effects on fear expression (measured at the start of the extinction session) from effects on extinction memory (measured during a drug-free retrieval test the following day). For those structures showing impairments in extinction memory, post-extinction infusions were also performed in order to dissociate acquisition $v s$ consolidation processes.

\section{MATERIALS AND METHODS}

\section{Subjects}

A total of 165 male Sprague-Dawley rats (Harlan Laboratories, Indianapolis, IN; 270-320 g) were housed and handled as described previously (Quirk et al, 2000). Briefly, rats were restricted to $18 \mathrm{~g}$ /day of standard laboratory rat chow, followed by training to press a bar for food on a variable interval schedule of reinforcement (VI-60). Pressing a bar for food ensures a constant level of activity in which freezing behavior can be reliably measured during training sessions (Quirk et al, 2000). All procedures were approved by the Institutional Animal Care and Use Committee of the University of Puerto Rico School of Medicine in compliance with the National Institutes of Health guidelines for the care and use of laboratory animals.

\section{Surgery}

After bar-press training, rats were anesthetized with intraperitoneal injections of a mixture of ketamine $(80 \mathrm{mg} / \mathrm{kg})$-xylazine $(10 \mathrm{mg} / \mathrm{kg})$ and were chronically implanted with a 26-gauge bilateral guide cannula (Plastics One, Roanoke, VA) in one of the four sites: IL $(+2.8 \mathrm{~mm}$ AP; $\pm 3.1 \mathrm{~mm} \mathrm{ML;}-3.8 \mathrm{~mm} \mathrm{DV}$; angled at $\left.30^{\circ}\right)$; PL $(+2.9 \mathrm{~mm} \quad$ AP; $\quad \pm 0.60 \mathrm{~mm}$ ML; $-2.6 \mathrm{~mm} \mathrm{DV}) ; \quad$ BLA $(-2.8 \mathrm{~mm} \mathrm{AP} ; \pm 5.0 \mathrm{~mm} \mathrm{ML} ;-7.6 \mathrm{~mm} \mathrm{DV})$; or ventral HPC (vHPC; $-6.30 \mathrm{~mm} \mathrm{AP;} \pm 5.00 \mathrm{~mm} \mathrm{ML} ;-5.5 \mathrm{~mm} \mathrm{DV}$ ) (Paxinos and Watson, 1998). For preextinction infusions into IL, an angled placement was used to avoid the overlying PL cortex. For post-extinction infusions into IL, bilateral cannula targeted IL vertically, with no angle $(+2.8 \mathrm{~mm} \mathrm{AP} ; \pm 0.60 \mathrm{~mm} \mathrm{ML} ;-4.2 \mathrm{~mm} \mathrm{DV})$. Acrylic cement was used to affix cannulas to the skull. After surgery, a triple antibiotic was applied, and an analgesic (Buprenorphine; $0.05 \mathrm{mg} / \mathrm{kg}$ ) was injected intramuscularly. Rats were allowed 7 days to recover from surgery prior to behavioral testing. Stainless steel obturators (33 gauge) were inserted into the guide cannulas to maintain patency until infusions were made.

\section{Histology}

Upon completion of experiments, rats were transcardially perfused with $0.9 \%$ saline followed by $10 \%$ buffered formalin. Brains were extracted and stored in a 30\% sucrose $/ 10 \%$ formalin solution. Coronal sections were cut $40 \mu \mathrm{m}$ thick, mounted on slides, and stained for Nissl bodies.

\section{Drug Infusions}

Muscimol (MUS) was used to enhance $\mathrm{GABA}_{\mathrm{A}}$ receptor activity, thereby inactivating target structures, and was administered either $30 \mathrm{~min}$ prior to extinction training or immediately after extinction training (extinction consolidation). Obturators were removed and injectors were placed into the guide cannulas. Injector tips extended $1.0 \mathrm{~mm}$ beyond the guide cannula. On the day prior to commencement of the experiment (Day 0), injectors were passed without infusion, and rats were acclimated for handling. MUS or saline vehicle (SAL) was infused at a rate of $0.2 \mu \mathrm{l} / \mathrm{min}$ for IL $(0.11 \mathrm{nmol} / 0.2 \mu \mathrm{l} /$ per side $)$, PL $(0.11 \mathrm{nmol} / 0.2 \mu \mathrm{l} /$ per side), BLA $(0.11 \mathrm{nmol} / 0.5 \mu \mathrm{l} /$ per side), or $0.16 \mu \mathrm{l} / \mathrm{min}$ for vHPC $(2.2 \mathrm{nmol} / 0.25 \mu \mathrm{l} / \mathrm{per}$ side $)$. After infusion, injectors were left in place for 1-2 min to allow the drug to diffuse. All doses were determined from published studies that infused muscimol into the BLA (Brioni et al, 1989; Wilensky et al, 2000), vHPC (Maren and Holt, 2004), IL, or PL (Laurent and Westbrook, 2009), as well as from pilot experiments in our laboratory.

\section{Behavior}

Auditory fear conditioning and extinction was performed in the same operant chambers (Coulbourn Instruments, Allentown, PA) located in sound-attenuating cubicles (Med Associates, Burlington, VT) throughout all phases of the experiment. The floor of the chambers consisted of stainless steel bars that delivered a scrambled electric footshock. Between experiments, shock grids and floor trays were cleaned with soap and water, and chamber walls were cleaned with wet paper towels. On Day 1, rats received five habituation tones $(30 \mathrm{~s}, 4 \mathrm{kHz}, 77 \mathrm{~dB} ; 3 \mathrm{~min}$ intertrial interval (ITI)), immediately followed by seven conditioning tones that co-terminated with footshocks $(0.5 \mathrm{~s}, 0.54 \mathrm{~mA})$. On Day 2, rats were returned to the chambers for extinction training, which consisted of 20 tones in the absence of footshock. On Day 3, rats were returned to the chambers and presented with 15 tones to test for extinction retrieval (the last retrieval trial was omitted from the analyses and figures, which show blocks of two trials). Food was available on the trained VI-60 schedule throughout all phases of the experiment. For post-extinction infusion experiments, the same number of trials was delivered, except the ITI was reduced to $1 \mathrm{~min}$ in order to reduce the duration of extinction training to disrupt consolidation as early as possible. 
Upon completion of behavioral experiments, a subset of rats were administered either MUS or SAL to assess the effects of localized inactivation on locomotor activity and anxiety levels in an open field apparatus $\left(91.5 \times 91.5 \times 61 \mathrm{~cm}^{3}\right)$, which was divided into peripheral (within $15.25 \mathrm{~cm}$ of the walls) and central $\left(61 \times 61 \mathrm{~cm}^{2}\right)$ regions of equal area, for $10 \mathrm{~min}$ (Mueller et al, 2009).

\section{Data Collection and Analysis}

Behavior was recorded with digital video cameras (Micro Video Products, Bobcaygeon, Ontario, Canada) and freezing was quantified from digitized video images using commercially available software (Freezescan, Clever Systems, Reston, VA). Trials were averaged in blocks of two, on which repeated-measures analysis of variance (ANOVA) or Student's two-tailed $t$-tests were made, followed by Tukey's post hoc comparisons (STATISTICA; Statsoft, Tulsa, OK). The amount of time freezing to the tone was expressed as a percentage of the tone presentation. In addition to freezing, suppression of bar pressing was also used as a measure of conditioned fear (Quirk et al, 2000) and analyzed using Student's $t$-test. A suppression ratio comparing pretone press rates with tone press rates was calculated as follows: (pretone-tone)/(pretone + tone). A value of 0 represents no suppression (low fear), whereas a value of +1 represents complete suppression of bar pressing (high fear). Total line crosses in the open field were counted to determine locomotor activity, and the percent of time spent in the center was used to determine anxiety, both of which were analyzed using Student's $t$-test.

\section{RESULTS}

\section{IL Inactivation had no Effect on Freezing, but Impaired Acquisition of Extinction and Extinction Memory}

To evaluate the role of IL in fear expression and extinction memory, we inactivated IL $30 \mathrm{~min}$ prior to extinction training on Day 2. Inactivation of IL did not affect freezing at the start of the session (Figure 1a), as indicated by similar levels of freezing during the first trial block (MUS: $58.5 \%$; SAL: $50.76 \% ; t_{22}=0.59 ; p=0.56$; Figure $\left.1 \mathrm{~b}\right)$. However, inactivation of IL impaired the acquisition of extinction (Figure 1b). Repeated-measures ANOVA of freezing during extinction training revealed no effect of group $\left(F_{1,18}=3.89\right.$; $p=0.064)$, but a main effect of trial block $\left(\mathrm{F}_{9,162}=10.75\right.$; $p<0.0001)$ and interaction of group with trial block $\left(\mathrm{F}_{9,162}=1.98 ; p=0.045\right)$. Post hoc comparisons confirmed that MUS-infused rats showed more freezing than controls in trial blocks $4-8$ (all $p$ values $<0.05$ ). Reduced acquisition of extinction was not a result of impaired locomotion, as inactivation of IL resulted in a comparable number of line crosses in an open field (MUS: 156.0 ; SAL: $163.1 ; t_{13}=0.46$; $p=0.65)$.

To test for extinction memory, rats were tested the following day (Day 3) drug free. Freezing in the MUS group was significantly higher than controls, indicating impaired retrieval of extinction memory (Figure 1b). Repeatedmeasures ANOVA revealed a main effect of trial block $\left(\mathrm{F}_{6,132}=22.32 ; \quad p<0.0001\right)$, of group $\left(\mathrm{F}_{1,22}=12.47\right.$; $p=0.019)$, and a significant interaction of group with trial block $\left(\mathrm{F}_{6,132}=4.42 ; p=0.004\right)$. Post hoc comparisons confirmed that MUS-infused rats showed significantly higher levels of freezing than controls in trial blocks 1 and 2 (all $p$ values $<0.05$ ). For suppression of bar pressing (Figure 1b, inset), IL inactivation did not alter suppression during the first trial block (MUS: 0.90; SAL: $0.99 ; t_{22}=1.11$; $p=0.28$; Figure $1 \mathrm{~b}$, inset). During extinction retrieval, there was a trend toward higher suppression in the MUS group that did not reach significance (MUS: 0.93; SAL: 0.76; $t_{22}=1.81 ; p=0.082$; Figure $1 \mathrm{~b}$, inset), most likely due to a ceiling effect in this measure.

Impaired retrieval of extinction could result from impaired acquisition of extinction and/or impaired consolidation of extinction (Quirk et al, 2000). To distinguish between these two roles of IL in extinction, we performed a post hoc matching of freezing levels in MUS and SAL groups at the end of extinction training (Supplementary Figure 1). Despite equivalent freezing throughout extinction training, MUS rats were still significantly impaired in extinction memory. Repeated-measures ANOVA of freezing during extinction retrieval revealed a main effect of group $\left(\mathrm{F}_{1,19}=9.98 ; p=0.005\right)$ and a significant interaction of group with trial block $\left(\mathrm{F}_{6,114}=4.37 ; p=0.0005\right)$. Post hoc comparisons confirmed that MUS-infused rats showed
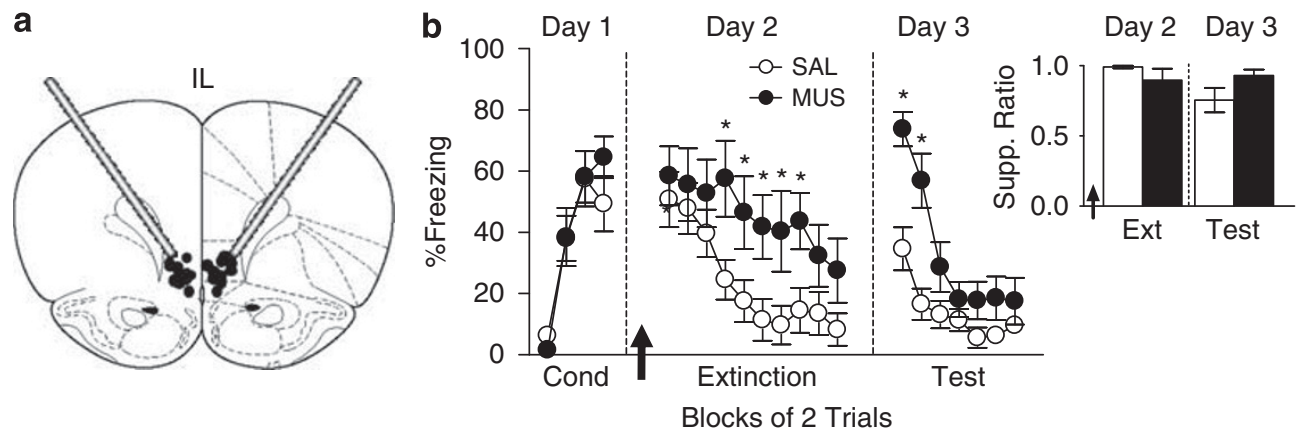

Figure I IL is necessary for extinction memory, but not fear expression. (a) Cannula placements in IL. (b) Inactivation of IL (MUS: $n=12 ; \mathrm{SAL}: n=12$ ) prior to extinction training (Day 2) did not affect conditioned freezing, but impaired the acquisition of extinction memory, as noted by higher levels of freezing during trial blocks 4-8. *p $<0.05$, Tukey's post hoc. During extinction retrieval (Day 3), MUS-infused rats displayed impaired extinction memory, as noted by higher levels of freezing during trial blocks $1-2$. * $p<0.05$, Tukey's post hoc. (b, inset) Effects on suppression were similar to freezing. Inactivation did not affect suppression on trial block I during extinction training (Day 2). During extinction retrieval (Day 3), however, MUS-infused rats displayed a trend toward higher suppression during the first trial block. $p=0.08$, Student's $t$-test. Data are represented as group averages, and bars indicate SEM. 
more freezing than controls in trial blocks $1-2$ (all $p$ values $<0.05$ ). This analysis suggests that impaired retrieval of extinction was not due to an inability of MUS rats to acquire extinction.

\section{PL Inactivation Reduced Freezing, but Did Not Impair Extinction Memory}

To evaluate the role of PL in fear expression and extinction memory, we inactivated PL (Figure 2a) prior to extinction training (Day 2). Unlike IL, inactivation of PL significantly reduced freezing from the start of the session (Figure $2 \mathrm{~b}$ ). Repeated-measures ANOVA of freezing during extinction training revealed a main effect of group $\left(\mathrm{F}_{1,23}=23.8\right.$; $p<0.0001)$ and a significant interaction of group with trial block $\left(\mathrm{F}_{9,207}=4.72 ; p<0.0001\right)$. Post hoc comparisons confirmed that MUS-infused rats showed less freezing than controls in trial blocks 1-5 (all $p$ values $<0.05$ ). On Day 3, freezing in the MUS group was the same as controls, indicating no impairment in extinction memory (Figure 2b). Repeated-measures ANOVA showed no effect of group $\left(\mathrm{F}_{1,23}=0.48 ; p=0.49\right)$, nor interaction of group with trial block $\left(\mathrm{F}_{6,138}=0.54 ; p=0.78\right)$. Bar-press suppression data were similar to freezing. Inactivation reduced suppression during the first trial block of extinction (MUS: 0.57 ; SAL: $0.96 ; t_{23}=3.40 ; p<0.01$; Figure $2 \mathrm{~b}$, inset), but not during the retrieval test (MUS: 0.60; SAL: $0.65 ; t_{23}=0.29$; $p=0.78$; Figure $2 \mathrm{~b}$, inset). Decreased freezing during extinction training was not accompanied by increases in general locomotion, as noted by a comparable number of line crosses in an open field (MUS: 202.6; SAL: 193.4; $t_{14}=0.55$; $p=0.59)$. Together, these data suggest that activity in PL is necessary for fear expression, but not extinction memory.

\section{BLA Inactivation Reduced Freezing and Impaired Extinction Memory}

Similar to PL, inactivation of BLA (Figure 3a) prior to extinction training caused a significant reduction in freezing (Figure 3b). Repeated-measures ANOVA of freezing during extinction training revealed a main effect of group $\left(\mathrm{F}_{1,21}=6.13 ; p=0.022\right)$ and significant interaction of group with trial block $\left(\mathrm{F}_{9,189}=5.51 ; p<0.0001\right)$. Post hoc comparisons confirmed that MUS-infused rats showed significantly less freezing in trial blocks $1-3$ (all $p$ values $<0.05$ ). On Day 3, freezing in the MUS group was significantly higher than controls, indicating poor extinction memory (Figure $3 \mathrm{~b}$ ). Repeated-measures ANOVA of freezing revealed a significant effect of group $\left(\mathrm{F}_{1,21}=9.41\right.$; $p=0.0058$ ) but no interaction of group with trial block $\left(\mathrm{F}_{6,126}=0.73 ; p=0.62\right)$. Post hoc comparisons confirmed that MUS-infused rats froze more than controls in trial blocks 1-3 (all $p$ values $<0.05$ ). Suppression data resembled freezing data. During extinction training, inactivation of BLA significantly reduced suppression during the first trial block (MUS: 0.28; SAL: 0.84; $t_{21}=3.63 ; \quad p=0.0015$; Figure $3 \mathrm{~b}$, inset), whereas during extinction retrieval, suppression was significantly higher than controls during the first trial block (MUS: 0.95; SAL: 0.53; $t_{21}=3.25$; $p=0.004$; Figure $3 \mathrm{~b}$, inset). Like PL, inactivation of BLA did not increase locomotion (MUS: 173.6; SAL: 160.6; $\left.t_{14}=1.26 ; p=0.23\right)$. Together, these data suggest that activity in BLA is necessary for both fear expression and extinction memory.

\section{vHPC Inactivation Reduced Freezing and Impaired Extinction Memory}

Similar to PL and BLA, inactivation of vHPC (Figure 4a) prior to extinction training significantly reduced conditioned freezing (Figure 4b). Repeated-measures ANOVA revealed a main effect of group $\left(\mathrm{F}_{1,26}=10.53 ; p=0.003\right)$ and significant interaction of group with trial block $\left(\mathrm{F}_{9,234}=2.14 ; p=0.027\right)$. Post hoc comparisons confirmed that MUS-infused rats froze less than controls in trial blocks 1-7 and 10 (all $p$ values $<0.05$ ). On Day 3, freezing in the MUS group was significantly higher than controls, indicating poor extinction memory (Figure $4 \mathrm{~b}$ ). Repeated-measures ANOVA revealed a main effect of group $\left(\mathrm{F}_{1,26}=4.94\right.$; $p=0.035)$ and a significant interaction of group with trial block $\left(\mathrm{F}_{6,156}=2.44 ; p=0.027\right)$. Post hoc comparisons confirmed that MUS-infused rats showed more freezing than controls in trial blocks 2-4 (all $p$ values $<0.05$ ). Suppression data were similar to freezing. Inactivation of vHPC reduced suppression during the first block of extinction (MUS: 0.52 ; SAL: $0.95 ; t_{26}=2.88 ; p=0.0079$; Figure $4 \mathrm{~b}$, inset), and increased suppression during the first block of retrieval (MUS: 0.93; SAL: $0.70 ; t_{26}=2.27$; a

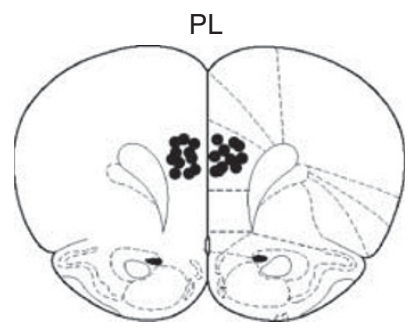

b

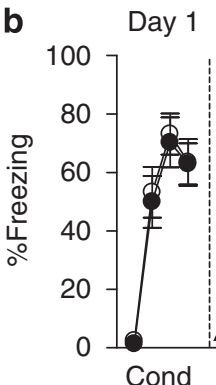

Day 2

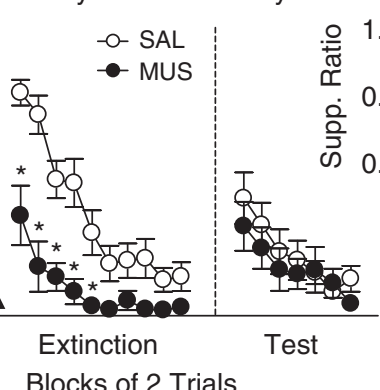

Day 2 Day 3

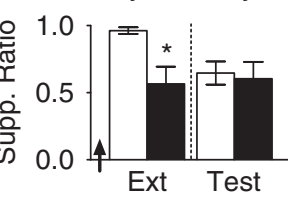

Figure $2 \mathrm{PL}$ is necessary for fear expression, but not extinction memory. (a) Cannula placements in PL. (b) Inactivation of PL (MUS: $n=\mid 4$; SAL: $n=1$ I) prior to extinction training (Day 2) reduced conditioned freezing during trial blocks I-5. * $<<0.05$, Tukey's post hoc. During extinction retrieval (Day 3), however, MUS-infused rats displayed normal levels of freezing. (b, inset) Effects on suppression were similar to conditioned freezing. Inactivation reduced suppression on trial block I during extinction training (Day 2). ${ }^{*} p<0.05$, Student's t-test. During extinction retrieval (Day 3), however, MUS-infused rats displayed normal levels of suppression during the first trial block. Data are represented as group averages. 


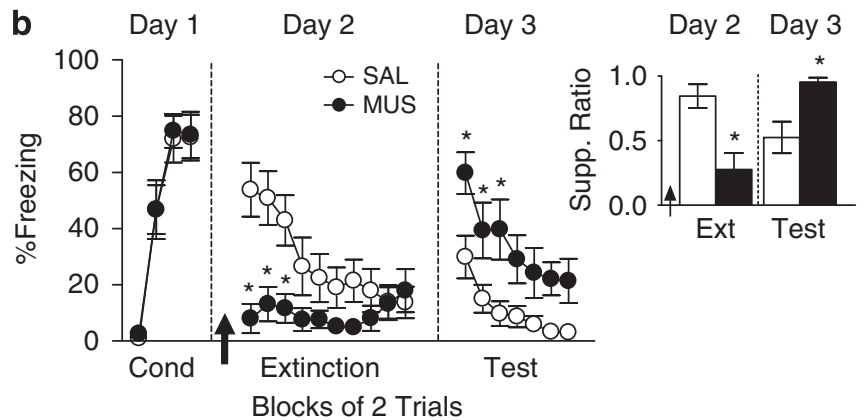

Figure 3 BLA is necessary for both fear expression and extinction memory. (a) Cannula placements in BLA. (b) Inactivation of BLA (MUS: $n=1$; ; SAL: $n=12$ ) prior to extinction training (Day 2) reduced conditioned freezing during trial blocks $1-3 .{ }^{*} p<0.05$, Tukey's post hoc. During extinction retrieval (Day 3), MUS-infused rats displayed higher levels of freezing during trial blocks $\mid-3$. $* 0<0.05$, Tukey's post hoc. (b, inset) Effects on suppression were similar to conditioned freezing. Inactivation reduced suppression on trial block I during extinction training (Day 2). * $p<0.05$, Student's $t$-test. During extinction retrieval (Day 3), MUS-infused rats displayed significantly higher levels of suppression during the first trial block. *p $<0.05$, Student's $t$-test. Data are represented as group averages.
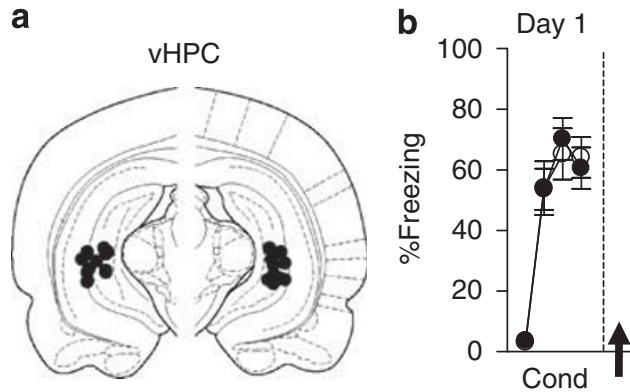

Day 2

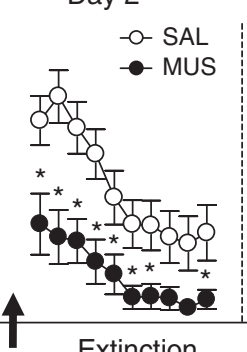

Blocks of 2 Trials
Day 3

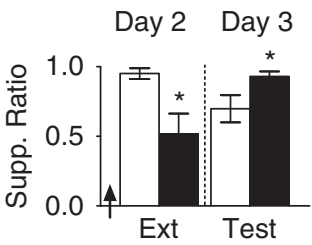

Figure 4 vHPC is necessary for both fear expression and extinction memory. (a) Cannula placements in vHPC. (b) Inactivation of vHPC (MUS: $n=14$; SAL: $n=14$ ) prior to extinction training (Day 2) reduced conditioned freezing during trial blocks I-7 and I0. * $p<0.05$, Tukey's post hoc. During extinction retrieval (Day 3), MUS-infused rats displayed significantly higher levels of freezing during trial blocks $2-4$. *p $<0.05$, Tukey's post hoc. (b, inset) Effects on suppression were similar to conditioned freezing. Inactivation reduced suppression on trial block I during extinction training (Day 2). $*<<0.05$, Student's t-test. During extinction retrieval (Day 3), MUS-infused rats displayed significantly higher levels of suppression during the first trial block. *p $<0.05$, Student's t-test. Data are represented as group averages.

$p=0.032$; Figure $4 \mathrm{~b}$, inset). As with the other structures, inactivation of vHPC did not alter locomotion (MUS: 179.0; SAL: $172.9 ; t_{11}=0.37 ; p=0.72$ ) nor anxiety levels as indicated by the percent time spent in the center of the open field (MUS: 15.74 ; SAL: $17.36 ; t_{11}=0.54 ; p=0.60$ ). Together, these data suggest that activity in vHPC (like BLA) is necessary for both fear expression and extinction memory.

\section{Post-Training Inactivation had no Effect in any Structure}

Impaired retrieval of extinction in the IL, BLA, and vHPC experiments suggests that processing within these structures during, and/or after, extinction training is necessary for long-term extinction memory. To dissociate between acquisition $v s$ consolidation processes, we ran a separate set of experiments in which the same doses of muscimol infused prior to extinction were infused immediately after extinction training in either IL, BLA, or vHPC. Also, the duration of the extinction training session was shortened (from 60 to $30 \mathrm{~min}$ ) in an attempt to interrupt the earliest stages of extinction consolidation. In no structure, however, did post-training inactivation impair extinction memory
(Supplementary Figure 2). Repeated-measures ANOVA of freezing during extinction retrieval showed no effect of group for any structure (all $p$ values $>0.4$ ), nor a significant interaction between group with trial block (all $p$ values $>0.3$ ). Bar-press suppression data largely mirrored freezing results, except for the fact that post-training inactivation of BLA caused reduced fear expression the following day (see Supplementary Figure 2). Together, these data suggest that activity necessary for extinction processing in IL, BLA, and vHPC occurs during extinction training, but not afterwards.

\section{DISCUSSION}

We re-examined the roles of prefrontal-amygdala-hippocampal circuits in fear expression and extinction memory using low-dose muscimol to locally inactivate specific structures in auditory fear conditioning. In PFC, we found that PL activity is necessary for fear expression but not extinction memory, whereas IL activity is necessary for extinction memory but not fear expression. We also observed that BLA and vHPC are necessary for both fear expression and extinction memory. 


\section{Fear Expression: PL not IL}

Lesion and inactivation studies of vmPFC have provided conflicting results regarding the role of vmPFC in fear expression and extinction (Quirk et al, 2000; Akirav et al, 2006; Garcia et al, 2006; Sierra-Mercado et al, 2006). One possible reason for this conflict is that previous studies did not distinguish between vmPFC subregions. Recently, we observed that inactivation of vmPFC (including IL and PL) impaired both fear expression and extinction (SierraMercado et al, 2006). On the other hand, Akirav et al (2006) observed that inactivation of vmPFC accelerated extinction (Akirav et al, 2006). Our present findings that inactivation of $\mathrm{PL}$, but not IL, reduces fear expression suggest that previous effects of vmPFC infusions on fear expression were confounded by the involvement of PL. Consistent with this idea, other reports showed that inactivation of PL reduces fear expression (Blum et al, 2006; Corcoran and Quirk, 2007; Laurent and Westbrook, 2009), and microstimulation of PL increased fear expression (Vidal-Gonzalez et al, 2006). Also consistent with these findings, Burgos-Robles et al (2009) observed sustained conditioned responses in PL neurons that paralleled the time course of conditioned freezing (Burgos-Robles et al, 2009).

Interestingly, we observed that inactivation of IL impaired the acquisition of extinction, which would seem to contradict many previous studies showing that IL lesion or inactivation does not affect the initial learning of extinction (Quirk and Mueller, 2008). However, because prior lesions involved PL, and an angled cannula placement was never used, a deficit in extinction acquisition was likely masked by PL dysfunction. Our present findings are consistent with some previous work, suggesting that IL is necessary for inhibiting fear responses during extinction. For example, Morrow et al (1999) reported that dopaminergic lesions in vmPFC impaired the acquisition of extinction. Furthermore, a recent study implicated IL in the acquisition of reextinction (but not extinction) of context fear (Laurent and Westbrook, 2009).

\section{Extinction Memory: IL not PL}

In contrast to fear expression, extinction memory was impaired by inactivation of IL, but not PL. A similar pattern of effects was recently reported for extinction of contextual fear (Laurent and Westbrook, 2009). Impairment of extinction memory with IL inactivation agrees with previous studies using IL infusions of TTX (Sierra-Mercado et al, 2006) or antagonists of NMDA receptors (BurgosRobles et al, 2007), $\beta$-adrenergic receptors (Mueller et al, 2008), MAP kinase (Hugues et al, 2004), protein synthesis (Santini et al, 2004; Mueller et al, 2008), or cannabinoid receptors (Lin et al, 2009). Together, these studies suggest that a calcium-mediated cascade in IL triggers protein kinases and protein synthesis necessary for long-term extinction memory. The lack of involvement of PL in extinction memory is somewhat surprising in light of a recent study showing that failure to retrieve extinction was correlated with increased tone responses of PL neurons during extinction training and testing (Burgos-Robles et al, 2009). On the other hand, our results suggest that PL activity during extinction training is important for fear expression, but not for extinction plasticity. We observed a similar role of activity in PL for acquisition of conditioned fear; PL inactivation reduced fear expression, but did not prevent fear learning (Corcoran and Quirk, 2007). Thus, PL is emerging as a modulator of fear expression, but not as a critical site of plasticity for either fear conditioning or extinction.

\section{vHPC and BLA Are Necessary for Both Fear Expression and Extinction Memory}

Inactivation of $\mathrm{vHPC}$ reduced fear expression, similar to what has been observed with lesions of vHPC (Maren and Holt, 2004). It has been previously shown that vHPC lesions reduce anxiety (McHugh et al, 2004), but this is unlikely to explain reduced freezing given that we observed no effect of vHPC inactivation in our measure of anxiety. Thus, unlike dHPC (Maren and Holt, 2004), the vHPC has a key role in expression of auditory conditioned fear.

We also observed that inactivation of vHPC during extinction training disrupted extinction memory. One possibility is that the impaired extinction was simply due to decreased fear expression during extinction training (Rescorla, 2003). This possibility is unlikely, however, given previous dissociations between fear expression and extinction memory (Akirav et al, 2006; Orsini and Maren, 2009; Laurent and Westbrook, 2009). Moreover, inactivation of PL reduced fear expression, but had no effect on extinction memory (see above). Our findings suggest that activity in vHPC during extinction training is required for subsequent expression of extinction memory, perhaps via potentiation of vHPC inputs to mPFC (Hugues et al, 2006; Hugues and Garcia, 2007). Another possibility is that the vHPC effects we observed were mediated via the context, as it has been shown that inactivation of vHPC reduces context fear (Biedenkapp and Rudy, 2009). Future experiments that vary contextual stimuli will be needed to disentangle the role of vHPC in the extinction of context $v s$ tone fears.

Reduced fear expression with BLA inactivation was expected, and agrees with previous inactivation studies (Muller et al, 1997; Maren and Holt, 2004). We also observed impaired extinction memory with BLA inactivation. Prior inactivation studies of BLA in extinction of auditory conditioning reported either no impairment (Akirav et al, 2006), or impairment in juvenile rats (Kim and Richardson, 2008). Our present finding that inactivation of BLA disrupted extinction memory is in apparent contradiction with negative effects from prior lesion studies (Sotres-Bayon et al, 2004; Anglada-Figueroa and Quirk, 2005). Interpretation of negative lesion findings is complicated by possible recovery of function from other structures. Therefore, our findings confirm that activity in BLA during extinction is necessary for extinction of auditoryconditioned fear in adult rats, in agreement with recent findings for context extinction (Laurent and Westbrook, 2008; Laurent et al, 2008). BLA activity during extinction is thought to trigger molecular cascades, as evidenced by numerous studies implicating BLA receptors and protein kinases in extinction (Falls et al, 1992; Lee and Kim, 1998; Lu et al, 2001; Lin et al, 2003; Hugues et al, 2004; Chhatwal et al, 2006; Herry et al, 2006; Sotres-Bayon et al, 2007; Kim 
et al, 2007), as well as the discovery of neurons in BLA that signal extinction (Herry et al, 2008).

\section{Post-Training Activity does not Appear to Be Important for Extinction}

We observed that post-training inactivation of IL did not affect extinction memory. This observation is somewhat surprising in light of recent studies showing that posttraining infusion of NMDAR antagonists CPP or ifenprodil in vmPFC interfered with extinction memory for both auditory (Burgos-Robles et al, 2007; Sotres-Bayon et al, 2009) and contextual (Laurent and Westbrook, 2008) fear conditioning. The involvement of NMDARs suggests that consolidation of extinction requires activation of glutamatergic circuits within IL following extinction. In support of this idea, IL neurons showed increased levels of bursting during (Chang et al, 2010) and following extinction (Burgos-Robles et al, 2007). However, in the present muscimol study, and in our prior inactivation study with TTX (Sierra-Mercado et al, 2006), we failed to find any effect of post-extinction inactivation on extinction memory. One possibility is that NMDA antagonists may have additional pharmacological actions, which could impair consolidation of extinction. For example, ifenprodil has been shown to block serotonergic receptors $(\mathrm{McCool}$ and Lovinger, 1995), voltage-gated calcium channels (Church et al, 1994), and adrendergic receptors (Chenard et al, 1991). CPP infused into MPFC was shown to increase dopamine and acetylcholine in the nucleus accumbens (Del Arco et al, 2008), as well as serotonin levels in mPFC (Ceglia et al, 2004), which could affect multiple processes including extinction.

\section{Putting It All Together}

Figure 5 compares the contributions of each of the structures we studied to fear expression and extinction memory. For fear expression, inactivation of PL and vHPC produced partial reductions in freezing, whereas inactivation of BLA resulted in a near-complete reduction in freezing. These findings for fear expression are consistent with a model in which BLA receives input from multiple sources, including PL and VHPC, and is the 'common final path' for fear expression (Figure 5a). Thus, PL and vHPC can serve as modulators of fear expression through their projections to BLA. vHPC could modulate BLA either directly (Pitkanen et al, 2000) or indirectly via the PL (Vertes, 2004; Gabbott et al, 2005). Convergence of inputs communicating contextual information, conditioned tone responses, and monoamines in PL could be necessary for the sustained conditioned activity of PL neurons, which mirrors fear expression (Burgos-Robles et al, 2009).

Inactivation of IL, vHPC, or BLA during extinction training impaired extinction memory. The idea that these three structures interact is suggested by the similar levels of extinction deficit observed (Figure 5b), and the similar timing of involvement (during, but not after extinction). BLA input to MPFC is shown to be potentiated by fear conditioning (Laviolette et al, 2005), and BLA input to $\mathrm{mPFC}$ is modulated by vHPC input (Ishikawa and Nakamura, 2003). It is possible therefore, that potentiation
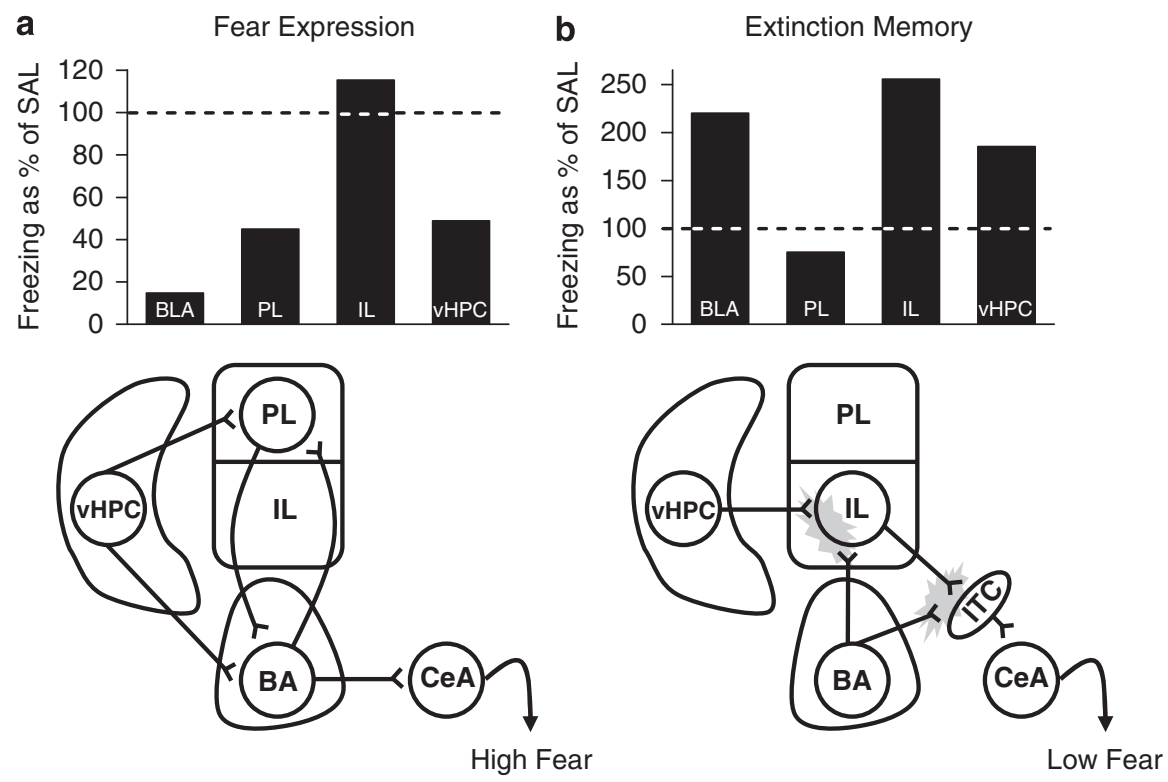

Extinction-related plasticity

Figure 5 Circuits of fear expression and extinction memory. (a) Fear expression. Freezing during the first trial block of extinction training for each muscimol group is represented as percent of saline controls (I00\%). PL and vHPC could augment fear expression through their projections to BLA, either in parallel or in series. (b) Extinction memory. Freezing during trial blocks I-2 of extinction retrieval (drug free) for each muscimol group is represented as percent of saline controls (I00\%). Extinction training results in plasticity (gray starburst) at VHPC and/or BLA inputs to IL. Extinction-related plasticity may also occur at IL inputs to intercalated (ITC) cell masses in the amygdala. After extinction, activation of ITCs would inhibit amygdala output via projections to $\mathrm{CeA}$, resulting in low fear. 
occurs at one or both of these inputs to IL during extinction. For example, recent evidence suggests that BLA is necessary for extinction acquisition (Herry et al, 2006; Sotres-Bayon et al, 2007). Extinction-related plasticity may also be occurring at IL inputs to intercalated (ITC) cells in the amygdala. ITC cells show NMDA-dependent plasticity (Royer and Paré, 2002), are necessary for extinction (Likhtik et al, 2008), and receive a robust input from IL (Vertes, 2004). In fact, it has been recently shown that extinction-induced potentiation of BLA inputs to ITCs is IL dependent (Amano et al, 2009), a finding that parallels the deficit in within-session extinction we observed with IL inactivation. After extinction, activation of ITCs would inhibit amygdala output via projections to CeA (Royer et al, 1999; Quirk et al, 2003), thereby reducing fear expression.

Anxiety disorders, such as post-traumatic stress disorder (PTSD), may be characterized by deficiencies in the ability to extinguish fear responses (Rothbaum and Davis, 2003; Milad et al, 2008, 2009). In healthy subjects, acquisition (Milad et al, 2007) and retrieval of extinction is associated with increased activity in the vmPFC (homologous to rodent IL) and HPC (Phelps et al, 2004; Kalisch et al, 2006; Milad et al, 2007). PTSD subjects show deactivation in these areas, coupled with hyperactivation of the dorsal anterior cingulate cortex (dACC; homologous to rodent PL) (Milad et al, 2009). Our findings suggest that it is during extinction training when activity in these areas is important. Consistent with this, BOLD activity in vmPFC and amygdala (Milad et al, 2007) was increased during extinction training in healthy subjects, but was depressed in PTSD subjects (Bremner et al, 2005; Milad et al, 2009). Thus, our rodent findings agree with human findings suggesting that the prefrontal-amygdala-hippocampal circuit is important during the initial learning of extinction. Our finding that the ventral HPC is necessary for fear expression and extinction suggests that the anterior HPC in humans would be particularly involved in these processes, as it is the homologue of the rodent vHPC (Moser and Moser, 1998). It is well documented that the HPC is smaller in PTSD subjects (Bremner et al, 1995; Gilbertson et al, 2002), and the anterior HPC may be particularly affected (Vythilingam et al, 2005; but see Bonne et al, 2008). Future imaging studies may focus on the role of the anterior HPC in fear expression and extinction learning, as well as its connections with vmPFC, dACC, and BLA.

\section{ACKNOWLEDGEMENTS}

This research was supported by MH058883, MH081975, and UPR President's Office to GJQ, an APA Diversity Program in Neuroscience fellowship and R36 MH089296 to DSM, and a UPR MARC Program fellowship to NPC. We thank Christian Bravo-Rivera and Aranza Torrado for assistance with histology. We also thank Mohammed Milad and Anthony Burgos-Robles for helpful comments on an earlier version of the manuscript.

\section{DISCLOSURE}

The authors declare no conflict of interest.

\section{REFERENCES}

Akirav I, Raizel H, Maroun M (2006). Enhancement of conditioned fear extinction by infusion of the GABA agonist muscimol into the rat prefrontal cortex and amygdala. Eur J Neurosci 23: 758-764.

Amano T, Unal CT, Paré D (2009). Synaptic basis of fear extinction in the amygdala: role of intercalated (ITC) neurons. Soc Neurosci Abstr 680: 10.

Anglada-Figueroa D, Quirk GJ (2005). Lesions of the basal amygdala block expression of conditioned fear but not extinction. J Neurosci 25: 9680-9685.

Biedenkapp JC, Rudy JW (2009). Hippocampal and extrahippocampal systems compete for control of contextual fear: role of ventral subiculum and amygdala. Learn Mem 16: 38-45.

Blum S, Hebert AE, Dash PK (2006). A role for the prefrontal cortex in recall of recent and remote memories. Neuroreport 17: 341-344.

Bonne O, Vythilingam M, Inagaki M, Wood S, Neumeister A, Nugent AC et al. (2008). Reduced posterior hippocampal volume in posttraumatic stress disorder. J Clin Psychiatry 69: 1087-1091.

Bremner JD, Randall P, Scott TM, Bronen RA, Seibyl JP, Southwick SM et al. (1995). MRI-based measurement of hippocampal volume in patients with combat-related posttraumatic stress disorder. Am J Psychiatry 152: 973-981.

Bremner JD, Vermetten E, Schmahl C, Vaccarino V, Vythilingam $\mathrm{M}$, Afzal $\mathrm{N}$ et al. (2005). Positron emission tomographic imaging of neural correlates of a fear acquisition and extinction paradigm in women with childhood sexual-abuse-related post-traumatic stress disorder. Psychol Med 35: 791-806.

Brioni JD, Nagahara AH, McGaugh JL (1989). Involvement of the amygdala GABAergic system in the modulation of memory storage. Brain Res 487: 105-112.

Burgos-Robles A, Vidal-Gonzalez I, Quirk GJ (2009). Sustained conditioned responses in prelimbic prefrontal neurons are correlated with fear expression and extinction failure. $J$ Neurosci 29: 8474-8482.

Burgos-Robles A, Vidal-Gonzalez I, Santini E, Quirk GJ (2007). Consolidation of fear extinction requires NMDA receptordependent bursting in the ventromedial prefrontal cortex. Neuron 53: 871-880.

Ceglia I, Carli M, Baviera M, Renoldi G, Calcagno E, Invernizzi RW (2004). The 5-HT receptor antagonist M100, 907 prevents extracellular glutamate rising in response to NMDA receptor blockade in the mPFC. J Neurochem 91: 189-199.

Chang CH, Berke JD, Maren S (2010). Single-unit activity in the medial prefrontal cortex during immediate and delayed extinction of fear in rats. PLOS ONE 5: e11971.

Chenard BL, Shalaby IA, Koe BK, Ronau RT, Butler TW, Prochniak MA et al. (1991). Separation of alpha 1 adrenergic and N-methylD-aspartate antagonist activity in a series of ifenprodil compounds. J Med Chem 34: 3085-3090.

Chhatwal JP, Stanek-Rattiner L, Davis M, Ressler KJ (2006). Amygdala BDNF signaling is required for consolidation but not encoding of extinction. Nat Neurosci 9: 870-872.

Church J, Fletcher EJ, Baxter K, MacDonald JF (1994). Blockade by ifenprodil of high voltage-activated $\mathrm{Ca} 2+$ channels in rat and mouse cultured hippocampal pyramidal neurones: comparison with N-methyl-D-aspartate receptor antagonist actions. $\mathrm{Br} \mathrm{J}$ Pharmacol 113: 499-507.

Corcoran KA, Desmond TJ, Frey KA, Maren S (2005). Hippocampal inactivation disrupts the acquisition and contextual encoding of fear extinction. J Neurosci 25: 8978-8987.

Corcoran KA, Quirk GJ (2007). Activity in prelimbic cortex is necessary for the expression of learned, but not innate, fears. J Neurosci 27: 840-844.

Del Arco A, Segovia G, Mora F (2008). Blockade of NMDA receptors in the prefrontal cortex increases dopamine and 
acetylcholine release in the nucleus accumbens and motor activity. Psychopharmacology (Berl) 201: 325-338.

Falls WA, Miserendino MJ, Davis M (1992). Extinction of fearpotentiated startle: blockade by infusion of an NMDA antagonist into the amygdala. J Neurosci 12: 854-863.

Gabbott PL, Warner TA, Jays PR, Salway P, Busby SJ (2005). Prefrontal cortex in the rat: projections to subcortical autonomic, motor, and limbic centers. J Comp Neurol 492: 145-177.

Garcia R, Chang CH, Maren S (2006). Electrolytic lesions of the medial prefrontal cortex do not interfere with long-term memory of extinction of conditioned fear. Learn Mem 13: 14-17.

Gilbertson MW, Shenton ME, Ciszewski A, Kasai K, Lasko NB, Orr SP et al. (2002). Smaller hippocampal volume predicts pathologic vulnerability to psychological trauma. Nat Neurosci 5: 1242-1247.

Gilmartin MR, McEchron MD (2005). Single neurons in the medial prefrontal cortex of the rat exhibit tonic and phasic coding during trace fear conditioning. Behav Neurosci 119: 1496-1510.

Herry C, Ciocchi S, Senn V, Demmou L, Muller C, Luthi A (2008). Switching on and off fear by distinct neuronal circuits. Nature 454: $600-606$

Herry C, Trifilieff P, Micheau J, Luthi A, Mons N (2006). Extinction of auditory fear conditioning requires MAPK/ERK activation in the basolateral amygdala. Eur J Neurosci 24: 261-269.

Hobin JA, Ji J, Maren S (2006). Ventral hippocampal muscimol disrupts context-specific fear memory retrieval after extinction in rats. Hippocampus 16: 174-182.

Hoover WB, Vertes RP (2007). Anatomical analysis of afferent projections to the medial prefrontal cortex in the rat. Brain Struct Funct 212: 149-179.

Hugues S, Chessel A, Lena I, Marsault R, Garcia R (2006). Prefrontal infusion of PD098059 immediately after fear extinction training blocks extinction-associated prefrontal synaptic plasticity and decreases prefrontal ERK2 phosphorylation. Synapse 60: 280-287.

Hugues S, Deschaux O, Garcia R (2004). Postextinction infusion of a mitogen-activated protein kinase inhibitor into the medial prefrontal cortex impairs memory of the extinction of conditioned fear. Learn Mem 11: 540-543.

Hugues S, Garcia R (2007). Reorganization of learning-associated prefrontal synaptic plasticity between the recall of recent and remote fear extinction memory. Learn Mem 14: 520-524.

Ishikawa A, Nakamura S (2003). Convergence and interaction of hippocampal and amygdalar projections within the prefrontal cortex in the rat. J Neurosci 23: 9987-9995.

Kalisch R, Korenfeld E, Stephan KE, Weiskopf N, Seymour B, Dolan RJ (2006). Context-dependent human extinction memory is mediated by a ventromedial prefrontal and hippocampal network. J Neurosci 26: 9503-9511.

Kim J, Lee S, Park K, Hong I, Song B, Son G et al. (2007). Amygdala depotentiation and fear extinction. Proc Natl Acad Sci USA 104: 20955-20960

Kim JH, Richardson R (2008). The effect of temporary amygdala inactivation on extinction and reextinction of fear in the developing rat: unlearning as a potential mechanism for extinction early in development. J Neurosci 28: 1282-1290.

Laurent V, Marchand AR, Westbrook RF (2008). The basolateral amygdala is necessary for learning but not relearning extinction of context conditioned fear. Learn Mem 15: 304-314.

Laurent V, Westbrook RF (2008). Distinct contributions of the basolateral amygdala and the medial prefrontal cortex to learning and relearning extinction of context conditioned fear. Learn Mem 15: 657-666.

Laurent V, Westbrook RF (2009). Inactivation of the infralimbic but not the prelimbic cortex impairs consolidation and retrieval of fear extinction. Learn Mem 16: 520-529.

Laviolette SR, Lipski WJ, Grace AA (2005). A subpopulation of neurons in the medial prefrontal cortex encodes emotional learning with burst and frequency codes through a dopamine D4 receptor-dependent basolateral amygdala input. J Neurosci 25: 6066-6075.

Lee H, Kim JJ (1998). Amygdalar NMDA receptors are critical for new fear learning in previously fear-conditioned rats. J Neurosci 18: 8444-8454.

Likhtik E, Popa D, Apergis-Schoute J, Fidacaro GA, Paré D (2008). Amygdala intercalated neurons are required for expression of fear extinction. Nature 454: 642-645.

Lin CH, Yeh SH, Lu HY, Gean PW (2003). The similarities and diversities of signal pathways leading to consolidation of conditioning and consolidation of extinction of fear memory. J Neurosci 23: 8310-8317.

Lin HC, Mao SC, Su CL, Gean PW (2009). The role of prefrontal cortex CB1 receptors in the modulation of fear memory. Cereb Cortex 19: 165-175.

Lu KT, Walker DL, Davis M (2001). Mitogen-activated protein kinase cascade in the basolateral nucleus of amygdala is involved in extinction of fear-potentiated startle. J Neurosci 21: RC162.

Maren S, Holt WG (2004). Hippocampus and Pavlovian fear conditioning in rats: muscimol infusions into the ventral, but not dorsal, hippocampus impair the acquisition of conditional freezing to an auditory conditional stimulus. Behav Neurosci 118: $97-110$.

McCool BA, Lovinger DM (1995). Ifenprodil inhibition of the 5hydroxytryptamine3 receptor. Neuropharmacology 34: 621-629.

McHugh SB, Deacon RM, Rawlins JN, Bannerman DM (2004). Amygdala and ventral hippocampus contribute differentially to mechanisms of fear and anxiety. Behav Neurosci 118: 63-78.

Milad MR, Orr SP, Lasko NB, Chang Y, Rauch SL, Pitman RK (2008). Presence and acquired origin of reduced recall for fear extinction in PTSD: results of a twin study. J Psychiatr Res 42: 515-520.

Milad MR, Pitman RK, Ellis CB, Gold AL, Shin LM, Lasko NB et al. (2009). Neurobiological basis of failure to recall extinction memory in posttraumatic stress disorder. Biol Psychiatry 66: $1075-1082$.

Milad MR, Quirk GJ (2002). Neurons in medial prefrontal cortex signal memory for fear extinction. Nature 420: 70-74.

Milad MR, Wright CI, Orr SP, Pitman RK, Quirk GJ, Rauch SL (2007). Recall of fear extinction in humans activates the ventromedial prefrontal cortex and hippocampus in concert. Biol Psychiatry 62: 446-454.

Morgan MA, Romanski LM, LeDoux JE (1993). Extinction of emotional learning: contribution of medial prefrontal cortex. Neurosci Lett 163: 109-113.

Morrow BA, Elsworth JD, Rasmusson AM, Roth RH (1999). The role of mesoprefrontal dopamine neurons in the acquisition and expression of conditioned fear in the rat. Neuroscience 92: 553-564.

Moser MB, Moser EI (1998). Functional differentiation in the hippocampus. Hippocampus 8: 608-619.

Mueller D, Olivera-Figueroa LA, Pine DS, Quirk GJ (2009). The effects of yohimbine and amphetamine on fear expression and extinction in rats. Psychopharmacology (Berl) 204: 599-606.

Mueller D, Porter JT, Quirk GJ (2008). Noradrenergic signaling in infralimbic cortex increases cell excitability and strengthens memory for fear extinction. J Neurosci 28: 369-375.

Muller J, Corodimas KP, Fridel Z, LeDoux JE (1997). Functional inactivation of the lateral and basal nuclei of the amygdala by muscimol infusion prevents fear conditioning to an explicit conditioned stimulus and to contextual stimuli. Behav Neurosci 111: 683-691.

Orsini CA, Maren S (2009). Glutamate receptors in the medial geniculate nucleus are necessary for expression and extinction of conditioned fear in rats. Neurobiol Learn Mem 92: 581-589.

Paxinos G, Watson C (1998). The Rat Brain in Stereotaxic Coordinates. Academic Press: San Diego. 
Phelps EA, Delgado MR, Nearing KI, LeDoux JE (2004). Extinction learning in humans: role of the amygdala and vmPFC. Neuron 43: 897-905.

Pitkanen A, Pikkarainen M, Nurminen N, Ylinen A (2000). Reciprocal connections between the amygdala and the hippocampal formation, perirhinal cortex, and postrhinal cortex in rat. A review. Ann N Y Acad Sci 911: 369-391.

Quirk GJ, Garcia R, Gonzalez-Lima F (2006). Prefrontal mechanisms in extinction of conditioned fear. Biol Psychiatry 60: 337-343.

Quirk GJ, Likhtik E, Pelletier JG, Paré D (2003). Stimulation of medial prefrontal cortex decreases the responsiveness of central amygdala output neurons. J Neurosci 23: 8800-8807.

Quirk GJ, Mueller D (2008). Neural mechanisms of extinction learning and retrieval. Neuropsychopharmacology 33: 56-72.

Quirk GJ, Russo GK, Barron JL, Lebron K (2000). The role of ventromedial prefrontal cortex in the recovery of extinguished fear. J Neurosci 20: 6225-6231.

Rescorla RA (2003). Protection from extinction. Learn Behav 31: 124-132.

Rothbaum BO, Davis M (2003). Applying learning principles to the treatment of post-trauma reactions. Ann N Y Acad Sci 1008: $112-121$.

Royer S, Martina M, Paré D (1999). An inhibitory interface gates impulse traffic between the input and output stations of the amygdala. J Neurosci 19: 10575-10583.

Royer S, Paré D (2002). Bidirectional synaptic plasticity in intercalated amygdala neurons and the extinction of conditioned fear responses. Neuroscience 115: 455-462.

Santini E, Ge H, Ren K, Pena DO, Quirk GJ (2004). Consolidation of fear extinction requires protein synthesis in the medial prefrontal cortex. J Neurosci 24: 5704-5710.
Sierra-Mercado D, Corcoran KA, Lebron-Milad K, Quirk GJ (2006). Inactivation of ventromedial prefrontal cortex reduces expression of conditioned fear and impairs subsequent recall of extinction. Eur J Neurosci 24: 1751-1758.

Sotres-Bayon F, Bush DE, LeDoux JE (2004). Emotional perseveration: an update on prefrontal-amygdala interactions in fear extinction. Learn Mem 11: 525-535.

Sotres-Bayon F, Bush DE, LeDoux JE (2007). Acquisition of fear extinction requires activation of NR2B-containing NMDA receptors in the lateral amygdala. Neuropsychopharmacology 32: 1929-1940.

Sotres-Bayon F, Cain CK, LeDoux JE (2006). Brain mechanisms of fear extinction: historical perspectives on the contribution of prefrontal cortex. Biol Psychiatry 60: 329-336.

Sotres-Bayon F, Diaz-Mataix L, Bush DE, LeDoux JE (2009). Dissociable roles for the ventromedial prefrontal cortex and amygdala in fear extinction: NR2B contribution. Cereb Cortex 19: 474-482.

Vertes RP (2004). Differential projections of the infralimbic and prelimbic cortex in the rat. Synapse 51: 32-58.

Vidal-Gonzalez I, Vidal-Gonzalez B, Rauch SL, Quirk GJ (2006). Microstimulation reveals opposing influences of prelimbic and infralimbic cortex on the expression of conditioned fear. Learn Mem 13: 728-733.

Vythilingam M, Luckenbaugh DA, Lam T, Morgan III CA, Lipschitz D, Charney DS, et al. (2005). Smaller head of the hippocampus in Gulf War-related posttraumatic stress disorder. Psychiatry Res 139: 89-99.

Wilensky AE, Schafe GE, LeDoux JE (2000). The amygdala modulates memory consolidation of fear-motivated inhibitory avoidance learning but not classical fear conditioning. $J$ Neurosci 20: 7059-7066.

Supplementary Information accompanies the paper on the Neuropsychopharmacology website (http://www.nature.com/npp) 